\title{
A agricultura na China: transformações setoriais e as relações comerciais com o Brasil
}

\author{
Paulo Dabdab Waquil
}

\begin{abstract}
Resumo
$\mathrm{O}$ artigo evidencia as transformações pelas quais a agricultura na China passou ao longo das últimas duas décadas, acompanhando um processo de profundas mudanças em toda a economia do país, que conduziu a maiores urbanização e industrialização. Ao longo do período, é muito forte o incremento na demanda por alimentos e matérias-primas, alterando as relações comerciais entre a China e o Brasil, abrindo oportunidades e novos desafios para a agricultura brasileira. Os resultados apresentados apontam para intensificação nos fluxos comerciais de produtos agrícolas, especialmente de produtos do complexo soja, primarização das exportações brasileiras, alterações nas políticas agrícolas e comerciais, ampliação dos investimentos estrangeiros e necessidade de acompanhamento e regulação deste processo.
\end{abstract}

Palavras-chave: Agricultura. China. Comércio internacional.

" Professor titular do Departamento de Economia e Relações Internacionais (Deri) e dos Programas de Pós-Graduação em Desenvolvimento Rural (PGDR) e em Agronegócios (PPGAN), da Faculdade de Ciências Econômicas (FCE), da Universidade Federal do Rio Grande do Sul (UFRGS). E-mail: waquil@ufrgs.br

http://dx.doi.org/10.5335/rtee.v24i50.7843

Submissão: 15/01/2018. Aceite: 28/06/2018. 


\section{Introdução}

Tem sido amplamente discutido como a China passou por marcantes transformações ao longo das duas últimas décadas, especialmente do ponto de vista econômico, apresentando elevadas taxas de crescimento do seu produto interno bruto, intensificação dos processos de urbanização e industrialização, melhorias na infraestrutura, liberalização e maior participação nos fluxos de comércio internacional. ${ }^{1}$ Entretanto, menor atenção é dada para as transformações que vêm ocorrendo nos espaços rurais e no setor agrícola.

Esta é a intenção do artigo: dar maiores atenção e visibilidade às significativas mudanças em curso no meio rural e na agricultura chinesa, utilizando um conjunto de dados, evidências e referências de outros trabalhos. Como resultado dessas transformações, também pretende-se trazer à luz algumas implicações em termos das relações comerciais entre a China e o Brasil, bem como as oportunidades e os desafios que se apresentam para a agricultura brasileira.

China e Brasil são considerados países emergentes, têm uma série de similitudes, mas também uma série de importantes diferenças e contrastes, que acabam resultando em complementaridades e possibilidades para a intensificação das suas relações comerciais. Ambos são países de dimensões amplas, com grande extensão de terras para a agricultura, ainda que com distintas limitações de uso da terra, com diversidades e desigualdades regionais. Os dois países também mantêm elevado contingente de pessoas no meio rural, e a agricultura ainda tem maior participação na formação dos seus respectivos produtos internos brutos do que nos países mais desenvolvidos.

Em 2001, a China passou a integrar a Organização Mundial do Comércio (OMC) e, a partir de então, ampliou sua participação no comércio internacional, estabelecendo maiores fluxos de exportações e importações e tornando-se rapidamente o principal parceiro comercial do Brasil, superando os Estados Unidos, a União Europeia e os parceiros brasileiros do Mercado Comum do Sul (Mercosul). Mas se, por um lado, a China intensificou o processo de industrialização e ampliou substancialmente as exportações de produtos manufaturados e semimanufaturados, por outro lado, as altas taxas de crescimento vêm conduzindo a aumentos de renda, maior diversificação do consumo de alimentos e ao consequente aumento da demanda por importações de produtos agrícolas e agroindustriais, a fim de suprir suas necessidades.

Desde a virada do século XXI, alguns relatórios do Departamento de Agricultura dos Estados Unidos (USDA) sobre a agricultura na China já destacam a 
importância dessas mudanças (GALE, 2002; GALE, 2013; GALE; HANSEN; JEWISON, 2015). Com o foco na agricultura e na alimentação na China e as perspectivas para o século XXI, os autores discutem a passagem de uma economia caracterizada por planejamento central e autossuficiência para uma economia mais dirigida por regras de mercado e integrada globalmente. Apontam que o crescimento da renda e a transição para estilos de vida mais urbanos tendem a elevar a demanda por alimentos, com maior direcionamento para carnes e produtos de maior valor agregado. Também esses relatórios dão bastante destaque para as negociações comerciais, o acesso da China à OMC, a redução de barreiras ao comércio e a maior abertura às importações de produtos agrícolas. Outros pontos enfatizados são o aprimoramento da infraestrutura de transportes e dos canais de comercialização, as reformas institucionais e políticas e a maior intensificação tecnológica.

Baseado nesta contextualização, o artigo tem como objetivos gerais evidenciar e discutir as transformações percebidas no meio rural e no setor agrícola na China, bem como nas relações comerciais com o Brasil, destacando algumas oportunidades e os desafios deste novo cenário.

O presente artigo, então, avança na seção 2 com a metodologia utilizada, incluindo as fontes de dados e os procedimentos adotados para a análise descritiva. A seguir, apresenta-se, na seção 3, um conjunto de informações sobre os recursos disponíveis e as variações na produção agrícola na China, analisando conjuntos de produtos de origem vegetal e produtos de origem animal e tecendo breves comparações com a situação brasileira. Na seção 4, sempre com o olhar das transformações percebidas ao longo do tempo, expõem-se os dados sobre as exportações e importações chinesas de produtos agrícolas. Após, na seção 5, apresentam-se os dados mais recentes sobre as exportações agrícolas e agroindustriais do Brasil para a China. Por fim, na seção 6, conclui-se com comentários sobre as oportunidades e os desafios deste novo cenário.

\section{Procedimentos metodológicos}

Os procedimentos adotados para atingir os objetivos do trabalho envolvem coleta, organização e análise de dados, a fim de evidenciar a disponibilidade dos recursos e as características da produção agrícola e dos fluxos comerciais da China, bem como suas relações com o Brasil. As fontes dos dados são: (i) a Organização para Agricultura e Alimentação (Food and Agriculture Organization - FAO), órgão vinculado à Organização das Nações Unidas (ONU) em sua base de estatísticas ${ }^{2}$ 
(statistical databases); e (ii) o Ministério da Agricultura, Pecuária e Abastecimento (Mapa) em sua base Agrostat. ${ }^{3}$

Os dados da FAO foram coletados para caracterizar as alterações ocorridas ao longo das últimas décadas. A fim de apresentá-los de forma mais sintética, são tabulados em intervalos de 20 anos até chegar ao período mais recente. De acordo com a disponibilidade, os dados referentes à população e à sua distribuição entre rural e urbana são estimados desde 1950, medidos em número de habitantes. Os demais dados, referentes a área agrícola, produção, exportações e importações, são calculados desde 1970. Os valores de área agrícola são expressos em hectares; os dados de produção, por grupo de produtos, em toneladas; e os dados de exportações e importações, também por grupo de produtos, em dólares norte-americanos. Calcula-se, ainda, o saldo comercial por grupo de produtos, resultante da diferença entre o valor das exportações e o valor das importações, expresso também em dólares norte-americanos.

Já, para a análise das relações comerciais entre a China e o Brasil, são considerados os dados do Mapa, utilizando apenas os valores mais recentes, referentes ao ano de 2016. Neste caso, são coletados os dados de exportações e importações, em dólares norte-americanos, por grupo de produtos. Também é calculado o percentual das exportações totais brasileiras de cada um dos grupos de produtos que é direcionado para a China, possibilitando uma análise do grau de dependência brasileira em relação àquele mercado.

\section{A agricultura na China: recursos e produção}

Algumas informações disponíveis nas bases de dados internacionais, como o World Bank e a FAO, ilustram que a China tem a responsabilidade de abastecer em torno de $22 \%$ da população mundial com apenas de $7 \%$ a $8 \%$ da área cultivável do planeta. Os dados apresentados na Tabela 1 mostram o crescimento populacional na China desde a segunda metade do século passado e a distribuição entre população rural e população urbana; em seguida, na Tabela 2, os dados ilustram o uso da terra ao longo do período.

Ainda que a população tenha diminuído seu ritmo de crescimento ao longo dos períodos considerados, as variações são muito elevadas nos períodos iniciais (49\%, entre 1950 e 1970; 43\%, entre 1970 e 1990), reduzindo para 16\%, entre 1990 e 2010, e para apenas $3 \%$ no período mais recente, entre 2010 e 2015 . Isso leva a China a figurar como o país mais populoso do mundo, com um contingente de mais de 1,4 bilhão de habitantes em 2015. Contudo, o que mais chama a atenção 
é o intenso processo de urbanização ocorrido nesses períodos. Em meados do século passado, os dados da FAO indicam que $88 \%$ da população residiam em áreas rurais, esse índice foi reduzido para $82 \%$, em 1970, e para $72 \%$ em 1990. A maior intensidade do processo de urbanização se deu a partir de 1990, deixando menos da metade da população (49\%) no meio rural, em 2010; e o dado mais recente (2015), de $43 \%$ (Tabela 1 ).

Tabela 1 - População rural e população urbana (em nº pessoas) na China, de 1950 a 2015

\begin{tabular}{l|r|r|r|r|r}
\cline { 2 - 6 } & \multicolumn{1}{|c|}{1950} & \multicolumn{1}{c|}{1970} & \multicolumn{1}{c|}{1990} & \multicolumn{1}{c|}{2010} & \multicolumn{1}{c|}{2015} \\
\hline População rural & 486.159 .282 & 676.848 .109 & 853.291 .588 & 677.440 .140 & 601.918 .586 \\
& $(88 \%)$ & $(82 \%)$ & $(72 \%)$ & $(49 \%)$ & $(43 \%)$ \\
População urbana & 67.685 .984 & 150.430 .895 & 327.700 .308 & 694.257 .198 & 805.386 .984 \\
& $(12 \%)$ & $(18 \%)$ & $(28 \%)$ & $(51 \%)$ & $(57 \%)$ \\
População total & 553.845 .266 & 827.279 .004 & 1.180 .991 .896 & 1.371 .697 .338 & 1.407 .305 .570 \\
\hline
\end{tabular}

Fonte: FAO.

Mesmo com o aumento populacional, os processos de êxodo rural e de urbanização de áreas rurais deixam atualmente um contingente muito menor de pessoas no meio rural, caindo de mais de 850 milhões de residentes rurais em 1990 para aproximadamente 600 milhões em 2015, o que evidencia menos mão de obra disponível no campo. E mais, várias análises mostram, assim como em quase todos os países do mundo, que a maior parte das migrações é de jovens rurais em direção às cidades, conduzindo também a um processo de envelhecimento no campo e à falta de sucessão familiar.

Seguindo uma tendência mundial, cada vez mais, estão presentes atividades não agrícolas no meio rural, gerando oportunidades de emprego e renda não agrícolas.

Nesses aspectos, já se notam semelhanças e contrastes em relação à realidade brasileira. O Brasil também apresentou crescimento populacional e um intenso processo de urbanização desde a segunda metade do século passado, mas tem atualmente uma população de 207 milhões de habitantes, em torno de $1 / 7$ da população chinesa, e uma distribuição que contrasta com o Brasil mais urbano, estando apenas $14 \%$ da população no meio rural.

$\mathrm{Na}$ China, em vista do grande contingente de pessoas no meio rural, a produção agrícola era, nas décadas passadas, predominantemente em pequena escala e voltada para subsistência, com a comercialização apenas de pequenos excedentes. Nos períodos mais recentes, vem mudando para uma produção mais especializada, em maior escala e voltada para o atendimento dos mercados. Mesmo assim, o 
acesso à terra ainda é controlado pelo governo, por meio de arrendamento às famílias produtoras rurais. Áreas de terras não podem ser compradas ou vendidas, apenas arrendadas. Em média, uma família detém uma área entre 0,5 e 1 hectare, fato que mais uma vez contrasta com a realidade brasileira. O Brasil tem uma estrutura fundiária bastante desigual, com um número elevado de pequenas e médias propriedades, mas um número reduzido de grandes propriedades, que detêm a maior parte das áreas agrícolas no país.

Em termos de área agrícola na China, os dados da FAO apontam a ampliação de pouco mais de 375 milhões de hectares em 1970 para 515 milhões de hectares atualmente (Tabela 2). Convém perceber que a maior parte deste incremento ocorreu no período 1970-1990, praticamente estabilizando desde então, o que sugere o esgotamento da capacidade de ampliação da área utilizada nas atividades de produção agrícola.

Tabela 2 - Área agrícola (em 1.000 ha) na China, de 1970 a 2014

\begin{tabular}{l|c|c|c|c}
\cline { 2 - 4 } & 1970 & 1990 & 2010 & 2014 \\
\hline Área agrícola & 375.518 & 506.592 & 515.368 & 515.358 \\
\hline
\end{tabular}

Fonte: FAO.

Da área total do país, em torno de 960 milhões de hectares, a área agrícola atualmente corresponde a 54\% e está distribuída entre as atividades de produção animal e produção vegetal, com pastagens e cultivos temporários ou permanentes. As áreas de florestas na China ocupam a parcela de $21 \%$ da área total, ficando os restantes $25 \%$ enquadrados como áreas urbanas, infraestrutura e áreas inaproveitadas. Em comparação com o Brasil, a dimensão total não é muito diferente, com grande extensão de terras, mas a distribuição é contrastante. O Brasil tem, como área total, em torno de 851 milhões de hectares, dos quais 33\% são área agrícola; $58 \%$, área de florestas; restando apenas $9 \%$ de áreas urbanas, infraestrutura e áreas inaproveitadas.

Quando se analisa a densidade populacional nas áreas rurais destinadas à agricultura, dividindo a população rural pela área agrícola, os resultados obtidos com os dados mais atuais mostram que na China se encontram em média 1,22 pessoas/hectare, enquanto no Brasil são somente 0,10 pessoa/hectare, confirmando o fato de um espaço rural muito mais povoado na China, com atividades agrícolas desenvolvidas em menores unidades de produção e mais intensivas em mão de obra.

De fato, a ampliação da área agrícola na China foi muito menor do que a ampliação na produção, como é visto logo adiante, o que leva a compreender o processo de intensificação dos sistemas de produção agrícola, com novos aportes técnicos, 
utilização de maiores quantidades de fertilizantes químicos e agrotóxicos e investimentos em biotecnologias. Entre as consequências dessa intensificação, além dos incrementos de produção e de produtividade, estão também custos de produção mais elevados e maiores danos ambientais, como erosão e perdas de solo, poluição das águas superficiais e dos lençóis freáticos e redução da vegetação nativa.

As disponibilidades de terras e água são vistas, cada vez mais, como fatores limitantes que restringem o crescimento da produção agrícola. Nas regiões mais montanhosas, as áreas cultivadas estão concentradas nos vales, onde também há melhor acesso à água. As áreas mais frágeis, mais suscetíveis a erosão e perdas de solo, estão sendo destinadas para a recuperação com pastagens e florestas. Há ainda algumas áreas próprias para a agricultura que vêm cedendo espaço para o processo de urbanização.

Com relação às políticas de apoio para o setor agrícola, a transição de uma economia caracterizada por planejamento central e autossuficiência para uma economia mais direcionada por regras de mercado e integrada globalmente deixa a agricultura chinesa mais influenciada pelas condições dos mercados. Dos anos 1950 aos anos 1990, a China sobretaxou seu setor agrícola pela compra governamental de produtos a preços abaixo dos preços de mercado, visando a subsidiar o consumo urbano e o desenvolvimento industrial. Mas a partir dos anos 1990, os preços pagos aos agricultores se aproximaram e até superaram os preços vigentes nos mercados internacionais. Com o ingresso na OMC e a consequente redução no controle e na intervenção governamentais sobre os preços praticados, novas formas de proteção e subsídios têm sido demandadas para garantir o abastecimento e a estabilidade social no meio rural (GALE, 2002).

Políticas de apoio doméstico, como pagamentos diretos e suporte de preços, foram introduzidas e têm sido ampliadas nos anos recentes (GALE, 2013). A fim de garantir o abastecimento de alimentos bem como a renda dos agricultores chineses, o país implementou políticas que incluem quatro tipos de subsídios: pagamentos diretos para a produção de grãos, subsídios na compra de insumos agrícolas, apoio à aquisição de maquinários agrícolas e subsídios na utilização de sementes melhoradas; também são implementadas medidas para a estocagem de produtos e práticas para a proteção ambiental (NI, 2013). Também maior atenção vem sendo dada à qualidade e à sanidade dos alimentos, à conveniência e à praticidade, ampliando a importância das indústrias agroalimentares e do segmento de distribuição (MENDEZ; DU; POPKIN, 2004).

Como resultado dessas transformações no uso dos recursos, da intensificação tecnológica e de alterações nas políticas de apoio e respondendo às novas demandas dos mercados, a produção agrícola na China também passou por marcantes alterações. Os dados apresentados nas Tabelas 3 e 4 mostram o crescimento da produção 
por grupos de produtos. Percebe-se que todos os grupos indicam crescimento, embora com variações diferenciadas entre eles, o que leva a uma nova configuração produtiva na agricultura chinesa.

A produção de cereais (arroz, milho, trigo, aveia, centeio, cevada) passou de 200 milhões de toneladas, em 1970, para mais de 559 milhões de toneladas em 2014 (último dado disponível), um incremento impressionante em termos absolutos, mas que em termos percentuais corresponde a $178 \%$, um dos menores entre os grupos de produtos vegetais. No caso das oleaginosas (principalmente a soja), a produção cresceu de 4 milhões de toneladas para pouco mais de 17 milhões, numa variação de 329\% no período. Já, nas fibras, o crescimento entre 1970 e 2010 (o dado de 2014 não está disponível) é relativamente menor, de $137 \%$.

Tabela 3 - Produção vegetal (em toneladas) na China, por grupos selecionados de produtos, de 1970 a 2014

\begin{tabular}{l|r|r|r|r}
\cline { 2 - 5 } & \multicolumn{1}{|c|}{1970} & \multicolumn{1}{c|}{1990} & \multicolumn{1}{c}{2010} & \multicolumn{1}{c}{2014} \\
\hline Cereais & 200.836 .854 & 404.719 .096 & 498.468 .274 & 559.315 .083 \\
Oleaginosas & 4.064 .095 & 9.742 .475 & 16.694 .266 & 17.444 .938 \\
Fibras & 2.659 .901 & 5.628 .792 & 6.300 .504 & n.d. \\
Frutas & 4.973 .710 & 20.952 .150 & 128.324 .500 & 160.998 .026 \\
Hortaliças & 42.017 .254 & 131.864 .457 & 545.435 .864 & 598.841 .626 \\
\hline
\end{tabular}

Legenda: n.d. = dado não disponível.

Fonte: FAO.

Contudo, as variações que mais chamam a atenção são as de frutas e hortaliças. São crescimentos, tanto em valor absoluto como relativo, mais elevados. No caso das frutas, de quase 5 milhões de toneladas, em 1970, para mais de $160 \mathrm{mi}-$ lhões de toneladas em 2014, numa taxa de crescimento que chega aos $3137 \%$ no período. $\mathrm{E}$, nas hortaliças, a passagem foi de 42 milhões de toneladas, em 1970, para praticamente 600 milhões de toneladas em 2014, alcançando um incremento de $1325 \%$ ao longo do período. Tais variações reforçam os argumentos de uma maior diversificação produtiva, atendendo às novas demandas e à maior incorporação de frutas e hortaliças nas dietas alimentares.

Da mesma forma, na produção de origem animal, também são percebidas grandes variações. A China sempre figurou como o maior produtor e consumidor de carne suína no mundo, mas mostrou incrementos consideráveis nos demais produtos. A produção de carne bovina passou de apenas 154 mil toneladas, em 1970, para mais de 6,5 milhões de toneladas em 2014, caracterizando uma elevação de $4138 \%$, uma taxa que se destaca em vista da pequena base produtiva inicial. $\mathrm{Na}$ produção de carne suína, a passagem de pouco mais de 6 milhões de toneladas, em 1970, para mais de 55 milhões de toneladas, em 2014, corresponde a uma variação 
de $802 \%$. Já, na produção de carne de frango, o crescimento foi de 970 mil toneladas, em 1970, para mais de 18 milhões em 2014, atingindo uma taxa de variação de $1773 \%$ no período, enquanto na produção de leite a passagem de menos de 2 milhões de toneladas, no início do período analisado, para mais de 42 milhões de toneladas, em 2014, corresponde a uma taxa de crescimento de $2073 \%$.

Tabela 4 - Produção animal (em toneladas) na China, por produtos selecionados, de 1970 a 2014

\begin{tabular}{l|r|r|r|r}
\cline { 2 - 4 } & \multicolumn{1}{|c|}{1970} & \multicolumn{1}{c|}{1990} & \multicolumn{1}{c}{2010} & \multicolumn{1}{c}{2014} \\
\hline Carne bovina & 154.972 & 1.121 .789 & 6.243 .716 & 6.567 .092 \\
Carne suína & 6.138 .780 & 23.559 .489 & 49.581 .462 & 55.390 .235 \\
Carne de frango & 970.739 & n.d. & 17.243 .053 & 18.186 .587 \\
Leite & 1.959 .253 & n.d. & 41.157 .040 & 42.577 .295 \\
\hline
\end{tabular}

Legenda: n.d. = dado não disponível.

Fonte: FAO.

Todas as taxas de crescimento da produção, seja de origem vegetal ou animal, são muito superiores às taxas de crescimento no uso dos recursos produtivos terra e mão de obra. Esse fato só é possível mediante intensificação dos processos produtivos, inovações tecnológicas, maior utilização de insumos externos, como sementes melhoradas, fertilizantes químicos, agrotóxicos e maquinários de pequeno porte. Também na produção animal, a intensificação produtiva se dá pela utilização de rações e medicamentos adquiridos fora das unidades produtivas. Tais mudanças caracterizam a transformação de uma agricultura muito intensiva em mão de obra para uma nova agricultura chinesa, mais intensiva em insumos externos e capital. Mas, como comentado anteriormente, são mudanças que vêm trazendo maiores custos de produção e impactos no meio ambiente.

\section{Maior inserção no cenário internacional: exportações e importações agrícolas}

Como o país mais populoso do mundo e com limitações na disponibilidade e no uso dos recursos produtivos, era surpreendente que até o final dos anos 1990 a China ainda permanecesse com reduzidas importações agrícolas (GALE, 2002). O planejamento centralizado e as políticas voltadas para garantir a autossuficiência, por meio das compras governamentais e subsídios aos consumidores urbanos, eram marcantes, garantindo a maior parte do abastecimento no país.

Após o ingresso como membro da OMC em 2001 e a liberalização comercial, reduzindo barreiras dos fluxos internacionais, a China passou a ter uma nova 
postura e ampliou suas relações comerciais com o restante do mundo. Com base no rápido processo de industrialização e no oferecimento de produtos manufaturados e semimanufaturados com baixos custos (particularmente em função dos baixos salários pagos e da pouca proteção social, em comparação com outros países mais industrializados), a China passou a dominar os principais mercados internacionais. Também nos mercados agrícola e agroindustrial, a China assumiu maior participação. Atualmente, o país é exportador de bens de alto valor agregado, mais intensivos em mão de obra. Entre os produtos agrícolas exportados pela China, aparecem peixes, frutas e hortaliças, além de produtos agroindustrializados (GALE, 2013).

Na Tabela 5, são apresentados os dados das exportações agrícolas da China, novamente por grupos de produtos, mas mensurados em mil dólares, ao longo das últimas décadas. Esses dados são analisados na sequência em conjunto com as importações (Tabela 6) e o saldo (diferença entre os valores das exportações e das importações) para cada um dos grupos (Tabela 7).

Também se pode visualizar o crescimento das exportações em todos os grupos, seja em valores absolutos (mil dólares) ou em percentuais. Entre todos os grupos apresentados, os que merecem maior destaque pelo crescimento absoluto do valor das exportações são as frutas e hortaliças, passando da exportação de quase 400 milhões de dólares, em 1970, para mais de 22 bilhões de dólares em 2013, de acordo com as informações mais recentes disponíveis na FAO. Esses resultados são bastante coerentes com o crescimento da produção, apresentado e discutido anteriormente. Os produtos que mais se destacam neste grupo são as frutas de clima temperado, como pêssego, maçã e ameixa, além de hortaliças, como o alho e a cebola. Também as exportações do grupo bebidas e tabaco apresentam elevado aumento em valor absoluto, atingindo mais de 5 bilhões de dólares em 2013.

Tabela 5 - Valor das exportações agrícolas (em US\$1.000,00) da China, por grupos de produtos selecionados, de 1970 a 2013

\begin{tabular}{l|r|r|r|r}
\cline { 2 - 4 } & \multicolumn{1}{|c|}{1970} & \multicolumn{1}{c|}{1990} & \multicolumn{1}{c|}{2010} & \multicolumn{1}{c}{2013} \\
\hline Cereais & 208.759 & 585.034 & 681.455 & 704.295 \\
Oleaginosas & 59.006 & 673.406 & 715.809 & 978.863 \\
Frutas e hortaliças & 397.765 & 2.747 .768 & 17.582 .329 & 22.574 .148 \\
Café & 14.479 & 4.712 & 110.528 & 228.732 \\
Bebidas e tabaco & 37.344 & 1.844 .504 & 3.711 .143 & 5.026 .498 \\
Carne bovina & 835 & 254.049 & 264.698 & 303.820 \\
Carne suína & 79.139 & 1.064 .121 & 1.038 .848 & 1.186 .648 \\
Carne de frango & 5.502 & 181.200 & 2.166 .483 & 2.500 .771 \\
\hline
\end{tabular}

Fonte: FAO. 
Visto de outra forma, em termos relativos, expressos por percentuais, as variações são muito elevadas. Devem ser analisadas, no entanto, com alguma cautela, pois são calculadas com base em valores iniciais (de 1970) muito reduzidos. Por exemplo, a taxa de variação ao longo do período analisado nas exportações de carne bovina é $45352 \%$, e a de carne de frango é $36286 \%$, mas, ainda assim, correspondem a um montante pouco significativo nos mercados internacionais. Nas frutas e hortaliças, grupo de produtos de maior relevância absoluta nas exportações agrícolas chinesas, a variação percentual entre 1970 e 2013 foi de 5575\%. As exportações chinesas de cereais são as que apresentam a menor variação percentual entre os grupos analisados, de apenas $237 \%$ no período.

$\mathrm{Ni}$ (2013) também afirma que a China tem vantagem comparativa na produção e na exportação de produtos mais intensivos em mão de obra, como frutas e hortaliças, embora as quantidades exportadas sejam pequenas, se vistas frente às quantidades destinadas para atender os mercados internos.

Olhando para a evolução das importações agrícolas pela China na Tabela 6, os valores são mais impressionantes e influenciam a dinâmica dos principais mercados agrícolas e agroindustriais e a formação dos preços internacionais. Em vista da urbanização e da industrialização do país, com elevadas taxas de crescimento da renda disponível pelas famílias e a maior diversificação do consumo de alimentos, há um forte incremento na demanda por importações de produtos agroalimentares.

A partir da redução das restrições às importações, a China vem se tornando cada vez mais dependente das importações de milho e soja (ou farelo) para a alimentação animal, além de carnes, produtos lácteos e outros produtos de origem animal. Também, em vista dos incrementos na renda e das mudanças nas preferências e nos hábitos dos consumidores, são perceptíveis as elevações na demanda por produtos de maior valor agregado, levando ao crescimento nas importações de vinhos, cervejas, café e chás, queijos, sorvetes e outros produtos agroindustrializados (GALE; HANSEN; JEWISON, 2015). Em seu relatório para o USDA, Gale, Hansen e Jewison (2015) também projetaram um contínuo crescimento nas importações agrícolas chinesas, ao menos até meados da próxima década. 
Tabela 6 - Valor das importações agrícolas (em US\$1.000,00) pela China, por grupos de produtos selecionados, de 1970 a 2013

\begin{tabular}{l|r|r|r|r}
\cline { 2 - 4 } & \multicolumn{1}{|c|}{1970} & \multicolumn{1}{c|}{1990} & \multicolumn{1}{c|}{2010} & \multicolumn{1}{c}{2013} \\
\hline Cereais & 551.607 & 3.480 .508 & 3.653 .325 & 7.372 .701 \\
Oleaginosas & 82.517 & 654.394 & 27.818 .762 & 42.825 .857 \\
Frutas e hortaliças & 125.232 & 1.549 .355 & 8.161 .168 & 13.216 .534 \\
Café & 11.817 & 13.419 & 172.046 & 289.600 \\
Bebidas e tabaco & 76.159 & 2.269 .133 & 6.622 .662 & 9.684 .368 \\
Carne bovina & 13.744 & 272.714 & 1.155 .191 & 3.767 .234 \\
Carne suína & 15.981 & 199.126 & 1.281 .688 & 2.558 .747 \\
Carne de frango & 15.123 & 257.276 & 2.875 .999 & 2.653 .500 \\
\hline
\end{tabular}

Fonte: FAO.

Em praticamente todos os grupos de produtos selecionados, o valor das importações pela China passou de alguns milhões de dólares, no ano de 1970, para a casa dos bilhões em 2013, com crescimento contínuo.

A entrada de cereais no país passou de 551 milhões de dólares para mais de 7 bilhões, num incremento de $1237 \%$ (o menor aumento percentual entre os grupos). Nas oleaginosas, especialmente a soja utilizada para alimentação animal e processamento e elaboração de outros produtos alimentícios industrializados, a variação nas importações é de 82 milhões de dólares, no início do período, para mais de 42 bilhões de dólares no final, atingindo o impressionante aumento relativo de $51799 \%$ (o maior aumento percentual entre os grupos).

Outros grupos de produtos que têm aumentos absolutos elevados nas importações chinesas são os de frutas e hortaliças e bebidas e tabaco, grupos esses que também figuravam com destaque nas exportações. Nos grupos de produtos de origem animal, o que tem maior incremento é a carne bovina, superando as importações de outras carnes (suína e frango).

Colocando juntos os dados sobre o valor das exportações e das importações, pode-se analisar os resultados em termos de saldo comercial por grupo de produtos selecionados. Estes valores estão expressos na Tabela 7, e alguns pontos merecem destaque. Primeiro, ao observar os dados mais recentes, em todos os grupos o saldo é negativo, indicando que o valor das importações supera o valor das exportações, exceto frutas e hortaliças. O grupo das oleaginosas é o que apresenta, de longe, o maior saldo negativo, atingindo 41 bilhões de dólares em 2013. A seguir, os grupos que também representam saldos bastante negativos são os de cereais, bebidas e tabaco, e carne bovina. O único grupo com saldo positivo é o de frutas e hortaliças, com o valor correspondente de 9 bilhões de dólares. Reunindo todos os grupos, o somatório do saldo comercial agrícola, levando em conta esses grupos de produtos 
selecionados, ultrapassou em 2013 a marca de 48 bilhões de dólares (com sinal negativo), confirmando a posição de maior importador mundial de produtos agrícolas e agroindustriais.

Tabela 7 - Saldo comercial (diferença entre os valores das exportações e das importações) agrícola (em US\$1.000,00) da China, por grupos de produtos selecionados, de 1970 a 2013

\begin{tabular}{l|r|r|r|r}
\cline { 2 - 4 } & \multicolumn{1}{|c|}{1970} & \multicolumn{1}{c|}{1990} & \multicolumn{1}{c}{2010} & \multicolumn{1}{c}{2013} \\
\hline Cereais & -342.848 & -2.895 .474 & -2.971 .870 & -6.668 .406 \\
Oleaginosas & -23.511 & 19.012 & -27.102 .953 & -41.846 .994 \\
Frutas e hortaliças & 272.533 & 1.198 .413 & 9.421 .161 & 9.357 .614 \\
Café & 2.662 & -8.707 & -61.518 & -60.868 \\
Bebidas e tabaco & -38.815 & -424.629 & -2.911 .519 & -4.657 .870 \\
Carne bovina & -12.909 & -18.665 & -890.493 & -3.463 .414 \\
Carne suína & 63.158 & 864.995 & -242.840 & -1.372 .099 \\
Carne de frango & -9.621 & -76.076 & -709.516 & -152.729 \\
\hline
\end{tabular}

Fonte: baseado nos dados das Tabelas 5 e 6.

Ao olhar ao longo do tempo, também chama atenção que o saldo aumenta em todos os grupos (sempre com sinal negativo, exceto para frutas e hortaliças, cujo sinal é positivo), correspondendo aos processos de relaxamento e redução nas restrições comerciais e à maior integração com os demais países. No somatório de todos os grupos, o saldo comercial com sinal negativo passou de 89 milhões de dólares, em 1970, para 1,3 bilhões, em 1990, 25,4 bilhões, em 2010, e finalmente mais de 48 bilhões em 2013, o dado mais recente disponível na base de dados da FAO. Até mesmo no caso da carne suína, em que a China aparecia como exportadora em 1970 e 1990, passou a ser importadora, com valores crescentes.

São marcantes, então, as transformações da agricultura chinesa nas últimas décadas, mudando a configuração produtiva, o uso de recursos e tecnologias e a geração de produtos. Como resultados desses processos, também são substanciais as mudanças nos fluxos comerciais, ilustradas nesta seção, atendendo a novas demandas criadas com processos de urbanização e industrialização, melhorias na infraestrutura de transportes e acesso a mercados, elevação da renda e diversificação das dietas alimentares. Cabe, assim, retomar a análise das relações comerciais entre a China e o Brasil, com complementaridades e abertura de oportunidades e desafios para as exportações brasileiras. 


\section{Relações comerciais entre o Brasil e a China}

O Brasil também passou por um processo de maior abertura ao comércio internacional a partir dos anos 1990, fortalecendo as relações comerciais com maior abrangência e aprofundamento. Buscou, então, maior aproximação com países que apresentavam interesses comuns e complementaridades estruturais. Um dos processos de integração foi a formação do Mercosul, removendo barreiras, facilitando o comércio inicialmente entre Argentina, Brasil, Paraguai e Uruguai e, depois, passando a combinar também outros países da América do Sul. Ainda que com dimensões distintas, todos são países de base agrícola, exportadores de bens semelhantes, com poucas possibilidades de complementação, de modo que os fluxos avançaram no início, mas logo se estabilizaram.

O Brasil buscou, então, alcançar novos mercados e, nesse sentido, encontrou na China um enorme parceiro comercial. Os fluxos de exportações e importações entre os dois países cresceram rapidamente, passando de 2,5 bilhões de dólares, no ano 2000, para 70 bilhões em 2011 (MASSUQUETTI et al., 2013). Também as relações comerciais se fortaleceram com outros países emergentes, levando à formação do grupo conhecido como Brics, que reúne Brasil, Rússia, Índia, China e África do Sul.

Desde 2009, a China é o maior parceiro comercial do Brasil, especialmente no que se refere aos mercados agrícolas e agroindustriais. De acordo com os dados apresentados na base de dados do Mapa, consultados em 2017, a China, em 2016, foi o destino de $32,99 \%$ das exportações agrícolas brasileiras, enquanto a União Europeia ficou com uma parcela de 17,04\%; os Estados Unidos, 6,45\%; e todos os demais países, com $43,52 \%$.

A Tabela 8, a seguir, apresenta os dados do Mapa com os valores das exportações e importações de produtos agrícolas entre o Brasil e a China no ano de 2016. No somatório da lista de produtos, o Brasil exportou para a China o correspondente ao valor de 20,8 bilhões de dólares, e as importações de produtos agrícolas da China ficaram em 1,1 bilhões de dólares no mesmo ano, gerando um saldo positivo em favor do Brasil de 19,7 bilhões de dólares.

Pela elevação da demanda chinesa por importações já apontada anteriormente, combinada com o avanço da produção de soja no Brasil nos anos recentes, não surpreende o fato de que os fluxos são fortemente dominados pelo complexo soja, especialmente grãos e farelo. Praticamente $70 \%$ das exportações agrícolas brasileiras para a China são produtos do complexo soja. Do total de 20,8 bilhões de dólares, 14,5 bilhões de dólares foram referentes aos produtos do complexo soja em 2016.

Teoria e Evidência Econômica - a. 24, n. 50, p. 6-25, jan./jun. 2018 
Outros produtos de maior relevância nos fluxos comerciais do Brasil para a China são produtos florestais (12\%), carnes (8\%), produtos do complexo sucroalcooleiro (4\%), couros e peleteria (2,7\%), fumo e seus produtos (1,3\%). Essa condição de pouca diversificação na pauta de produtos exportados para a China cria a situação de dependência de um único produto brasileiro em relação aos mercados chineses, com maiores riscos.

Já, no que se refere às importações brasileiras de produtos agrícolas oriundos da China, são poucos os que se destacam, com saldos em favor dos chineses. São os casos de chás e especiarias, frutas e hortaliças, pescados, rações, fibras e produtos têxteis.

Tabela 8 - Valor das exportações e importações agrícolas (em US\$ 1.000,00) do Brasil para a China, por grupo de produtos, em 2016

\begin{tabular}{|c|c|c|c|}
\hline & Exportações & Importações & $\begin{array}{c}\text { Saldo } \\
\text { (exp. menos imp.) }\end{array}$ \\
\hline Total & 20.831 .138 & 1.124 .443 & 19.706 .695 \\
\hline Complexo soja & 14.562 .535 & - & 14.562 .535 \\
\hline Produtos florestais & 2.411 .697 & 163.732 & 2.247 .965 \\
\hline Carnes & 1.752 .351 & 54.520 & 1.697 .832 \\
\hline Complexo sucroalcooleiro & 839.194 & 3.073 & 836.121 \\
\hline Couros e peleteria & 573.046 & 7.231 & 565.815 \\
\hline Fumo e seus produtos & 279.751 & 2.091 & 277.660 \\
\hline Demais produtos de origem vegetal & 105.204 & 43.847 & 61.357 \\
\hline Produtos oleaginosos (exceto soja) & 61.237 & 1.527 & 59.710 \\
\hline Sucos & 59.310 & 309 & 59.000 \\
\hline Cereais, farinhas e preparações & 29.649 & 14.056 & 15.593 \\
\hline Café & 13.772 & - & 13.772 \\
\hline Demais produtos de origem animal & 7.698 & 6.244 & 1.453 \\
\hline Produtos apícolas & 1.179 & - & 1.179 \\
\hline Bebidas & 823 & 63 & 760 \\
\hline Animais vivos (exceto pescados) & 23 & - & 23 \\
\hline Lácteos & 1 & - & 1 \\
\hline Plantas vivas e floricultura & 32 & 65 & -33 \\
\hline Cacau e seus produtos & 370 & 747 & -377 \\
\hline Chá, mate e especiarias & 242 & 3.972 & -3.730 \\
\hline Frutas (inclui nozes e castanhas) & 1.397 & 9.868 & -8.471 \\
\hline Produtos alimentícios diversos & 7.204 & 23.671 & -16.467 \\
\hline Rações para animais & 1.813 & 68.570 & -66.757 \\
\hline Pescados & 9.219 & 148.387 & -139.169 \\
\hline Fibras e produtos têxteis & 113.363 & 274.969 & -161.605 \\
\hline Produtos hortícolas, leguminosas, raízes e tubérculos & 29 & 297.501 & -297.472 \\
\hline
\end{tabular}

Fonte: Mapa. 
Tabela 9 - Participação das exportações agrícolas (em \%) para a China em relação ao total exportado pelo Brasil, por grupo de produtos, em 2016

\begin{tabular}{l|c}
\multicolumn{1}{c|}{ Produtos } & $\%$ \\
\hline Total & 25 \\
Complexo soja & 57 \\
Produtos florestais & 24 \\
Carnes & 12 \\
Complexo sucroalcooleiro & 7 \\
Couros e peleteria & 23 \\
Fumo e seus produtos & 13 \\
Demais produtos de origem vegetal & 10 \\
Produtos oleaginosos (exceto soja) & 24 \\
Sucos & 3 \\
Cereais, farinhas e preparações & 1 \\
Café & - \\
Demais produtos de origem animal & 1 \\
Produtos apícolas & 1 \\
Bebidas & - \\
Animais vivos (exceto pescados) & - \\
Lácteos & - \\
Plantas vivas e floricultura & - \\
Cacau e seus produtos & - \\
Chá, mate e especiarias & - \\
Frutas (inclui nozes e castanhas) & - \\
Produtos alimentícios diversos & - \\
Rações para animais & 1 \\
Pescados & 1 \\
Fibras e produtos têxteis & 4 \\
Produtos hortícolas, leguminosas, raízes e tubérculos & 7 \\
\hline
\end{tabular}

Fonte: Mapa.

Além de compreender as fortes concentração e dependência de um único produto nos mercados da China, é interessante olhar a participação da China nos fluxos de exportações de produtos agrícolas do Brasil (Tabela 9). Com isso, pode-se analisar a dependência que o Brasil tem da China para cada um dos grupos de produtos. Nesse sentido, além dos dados da Tabela 8, coletaram-se os dados das exportações totais brasileiras para todos os destinos, e compilou-se a razão entre os valores direcionados para a China em relação aos totais.

De todas as exportações agrícolas do Brasil, medidas pelo valor das exportações, $25 \%$ foram destinadas para a China no ano de 2016. Mas alguns produtos se destacam pela maior participação do destino China, enquanto outros são mais distribuídos entre diversos destinos. Do total de exportações do complexo soja, 57\% 
são destinadas para a China, o maior percentual entre todos os produtos. Assim, confirma-se a dependência indicada anteriormente: nos mercados da China, o Brasil depende da soja; visto pelo outro ângulo, nos mercados da soja, o Brasil também depende da China.

Entre outros grupos de produtos com maior direcionamento e participação da China no valor das exportações totais brasileiras, estão produtos florestais (24\%), produtos oleaginosos (24\%), exceto soja, couros e peleteria (23\%), fumo e seus produtos $(13 \%)$ e carnes (12\%). No restante, o Brasil mantém uma pauta mais diversificada entre os destinos das exportações agrícolas.

Fechando esta seção, ainda vale a pena comentar que, apesar da rápida expansão nos fluxos entre os países, nem sempre ela foi livre de tensões. Ao longo do período mais recente, algumas disputas e restrições por questões sanitárias, técnicas ou ambientais têm sido relevantes. E, como ponto final, mais do que os fluxos comerciais, as relações entre Brasil e China na agricultura têm envolvido, mais recentemente, investimentos externos entre os dois países, não apenas nos setores produtivos agrícola e agroindustrial, mas também em infraestrutura e energia.

\section{Considerações finais}

Foram evidenciadas as marcantes transformações pelas quais a agricultura da China passou nas últimas décadas: limitações para a ampliação do uso de recursos produtivos (como terra e água), processo intenso de urbanização, mudanças tecnológicas, maior intensificação no uso de insumos externos, mudanças nas políticas de apoio ao setor e, principalmente, maior abertura dos mercados, expandindo os fluxos de exportações e importações. Dois pontos ainda merecem comentário.

Primeiro, seguindo as análises de Medeiros e Cintra (2015), que estudaram os impactos da ascensão chinesa nos mercados latinoamericanos, há dois tipos de efeitos sobre a economia brasileira. Um é o efeito demanda, já bem discutido ao longo do artigo, representado pelo incremento na demanda por importações de matérias-primas e alimentos pela China, com impactos marcantes nas exportações agrícolas brasileiras, principalmente de produtos do complexo soja. Há também o efeito estrutura, que altera a pauta de produtos nos fluxos entre os dois países, conduzindo à primarização das exportações brasileiras, em vista da maior dependência de produtos com menor valor agregado, como as commodities soja e minérios, o que tende a elevar a vulnerabilidade do país no cenário internacional. 
O segundo ponto a considerar são os altos investimentos realizados pelas empresas chinesas no exterior e que interessam particularmente no Brasil. Em 2013, a China já aparecia como o maior investidor estrangeiro no Brasil, embora com forte predominância nas indústrias de alta tecnologia, telecomunicações, energia e indústria automobilística. No entanto, nos anos recentes, a China passou a estimular também os investimentos externos nos setores agrícola e agroindustrial, por meio da compra ou do arrendamento de terras para produção e da aquisição de empresas que atuam no processamento e na distribuição dos produtos agroalimentares.

$\mathrm{Na}$ medida em que a China se tornou um grande importador de alimentos, as estratégias para garantir a segurança alimentar de sua população passaram a incluir o controle sobre as importações, e, nesse sentido, o governo passou a estimular os investimentos externos feitos pelas empresas chinesas. Conforme referido por Gooch e Gale (2015), citando dados do Ministério do Comércio da China, em 2014 já eram mais de 300 empresas chinesas com investimentos em 46 países, com projetos agrícolas, florestais e de pesca. Também de acordo com o Ministério da Agricultura da China, empresas chinesas já cultivavam mais de 230.000 hectares em terras estrangeiras, visando a abastecer os mercados do país.

Esses investimentos das empresas chinesas vêm sendo apoiados pelo governo da China por meio de subsídios, financiamentos direcionados, serviços de informação e treinamento. Iniciaram com o acesso à terra em países menos desenvolvidos, pela compra ou pelo arrendamento de terras mais baratas em regiões com infraestrutura mais deficitária e baixos índices de produtividade, como o sudeste da Ásia e a África, e avançaram para outras regiões, como países do leste da Europa e países da América Latina.

Mais recentemente, os investimentos diretos das empresas chinesas evoluíram para toda a cadeia produtiva, incluindo plantas processadoras de alimentos, logística e distribuição e trading companies. Entre os principais segmentos atingidos, estão os de cereais, oleaginosas e carnes, visando à garantia do abastecimento de insumos para a alimentação animal e de proteínas de origem animal, como as carnes e os produtos lácteos, cuja demanda continua em crescimento. Por fim, mesmo que o desenvolvimento de bases sólidas de oferta de produtos em terras estrangeiras seja lento, e algumas experiências não se mostraram bem-sucedidas, é possível que, num futuro próximo, uma maior parcela das exportações agrícolas brasileiras para a China esteja nas mãos de companhias dirigidas pelos chineses, conferindo à China maior controle sobre os mercados globais. 


\title{
Agriculture in China: transformations and trade relations with Brazil
}

\begin{abstract}
The article highlights the transformations that agriculture in China has undergone over the past two decades, following a process of profound changes in the country's economy, which has led to greater urbanization and industrialization. Throughout the period, the demand for food and raw materials is increasing, changing trade relations between China and Brazil, opening opportunities and new challenges for Brazilian agriculture. The results show an intensification in the commercial flows of agricultural products, especially of products of the soybean complex, the primarization of Brazilian exports, changes in agricultural and commercial policies, expansion of foreign investments and the need to follow up and regulate this process.
\end{abstract}

Keywords: Agriculture. China. International trade.

\section{La agricultura en China: transformaciones sectoriales y las relaciones comerciales con Brasil}

\section{Resumen}

El artículo evidencia las transformaciones que la agricultura en China ha pasado a lo largo de las últimas dos décadas, acompañando un proceso de profundos cambios en toda la economía del país, que condujo a la mayor urbanización e industrialización. A lo largo del período, es muy fuerte el incremento en la demanda de alimentos y materias primas, alterando las relaciones comerciales entre China y Brasil, abriendo oportunidades y nuevos desafíos para la agricultura brasileña. Los resultados presentados apuntan a la intensificación en los flujos comerciales de productos agrícolas, especialmente de productos del complejo soja, primarización de las exportaciones brasileñas, cambios en las políticas agrícolas y comerciales, ampliación de las inversiones extranjeras y la necesidad de acompañamiento y regulación de este proceso.

Palabras clave: Agricultura. China. Comercio internacional. 


\section{Notas}

1 Sobre o tema, consultar o trabalho de Jiang e Lin (2012).

2 Endereço da base da dados: <http://www.fao.org/faostat>. Acesso em: 31 jul. 2017.

3 Endereço da base de dados: <http://www.agricultura.gov.br/agrostat>. Acesso em: 31 jul. 2017.

\section{Referências}

GALE, Fred (Ed.). China's food and agriculture: issues for the 21st century. USDA: Economic Research Service, Market and Trade Economics Division, 2002. (Agriculture Information Bulletin, n. 775).

. Growth and evolution in China's agricultural support policies. USDA: Economic Research Service, 2013.

GALE, Fred; HANSEN, James; JEWISON, Michael. China's growing demand for agricultural imports. USDA: Economic Research Service, 2015.

GOOCH, Elizabeth; GALE, Fred. Get ready for chinese overseas investment in agriculture. Choices, Milwaukee, WI, USA, v. 30, n. 2, p. 1-5, 2015.

JIANG, Z.; LIN, B. China's energy demand and its characteristics in the industrialization and urbanization process. Energy Policy, Elsevier, v. 49, p. 608-615, 2012.

MASSUQUETTI, Angélica et al. O. As relações comerciais agrícolas entre Brasil e China no período 2000-2011: perspectivas para o agronegócio brasileiro. Revista Nexos Econômicos, Salvador, BA, v. 7, n. 2, p. 131-148, 2013.

MEDEIROS, Carlos A.; CINTRA, Maria R. V. P. Impacto da ascensão chinesa sobre os países latinoamericanos. Revista de Economia Política, São Paulo, v. 35, n. 1, p. 28-42, 2015.

MENDEZ, M; DU, S.; POPKIN, B. Urbanization, income and the nutrition transition in China: a case study. In: Globalization of food systems in developing countries: impact on food security and nutrition, Rome: FAO Food and Nutrition Paper, 2004. v. 83. p. 169-194.

NI, Hongxing. Agricultural domestic support and sustainable development in China. Geneva: International Centre for Trade and Sustainable Development, 2013. n. 47. p. 1-45. 